\title{
Amyloidosis of the liver causing jaundice
}

\author{
ROBERT COX \\ F.R.C.S.
}

Department of Surgery, East Birmingham Hospital, Bordesley Green East, Birmingham

\begin{abstract}
Summary
A case of primary amyloidosis of the liver causing jaundice is described. Attention is drawn to the rarity of the condition. A precise pre-operative diagnosis would have spared the patient a laparotomy.

Introduction

Patients suffering from amyloidosis frequently have liver involvement. Although some of the stigmata of chronic diffuse liver disease may be seen and some liver function tests may be abnormal, particularly the bromsulphthalein excretion and alkaline phosphatase, the presence of hepatic involvement in amyloidosis is usually of little clinical significance (Brandt, Cathcart and Cohen, 1968). Jaundice, except as a terminal event, is extremely rare. A case of amyloidosis presenting with abdominal pain and jaundice is described.
\end{abstract}

\section{Case report}

A 65-year-old male Caucasian presented with a 3-month history of increasing central abdominal pain and one month of deepening jaundice. This was accompanied by dark urine and pale stools. He had lost $4 \mathrm{~kg}$ in weight over 9 months and had a 4-year history of episodic vomiting at monthly intervals. Eleven years earlier he had undergone cholecystectomy and exploration of the common bile duct for flatulent dyspepsia. The patient made an uncomplicated recovery from this procedure.

Examination showed a deeply jaundiced man with evidence of recent weight loss. A smooth, nontender liver was palpable $2 \mathrm{~cm}$ below the costal margin.

Liver function tests were as follows, serum total protein $71 \mathrm{~g} / \mathrm{l}$; serum albumin $33 \mathrm{~g} / \mathrm{l}$; serum bilirubin $340 \mu \mathrm{mol} / 1$; serum alkaline phosphatase 1700 i.u./l (normal 30-130 i.u./l, serum lactate dehydrogenase 188 i.u./l (normal 50-300 i.u./l), serum alanine amino transferase 121 i.u./l (normal 5-40 i.u./l), serum aspartate amino transferase 214 i.u./l (normal 5-40 i.u./l). Urine testing showed bilirubin ++ . A barium meal was normal, but a liver scan showed reduced uptake of colloid in both lobes with an enlarged right lobe. Other investigations included an ESR of $53 \mathrm{~mm} / \mathrm{hr}$, normal urinalysis and plasma protein electrophoresis showing no monoclonal band. Further liver function tests $\infty$ showed a deepening of the jaundice, and laparotomy was undertaken.

The significant findings at operation were a $\overrightarrow{0}$ smooth, enlarged liver, a common bile duct $0.7 \mathrm{~cm}$ 응 in diameter and enlarged lymph nodes in the lesser omentum. An operative cholangiogram showed $\vec{z}$ absent filling of the left hepatic duct. The common bile duct was opened and cholangiography per- $\stackrel{\bigcirc}{\rightarrow}$ formed using a catheter. This showed both ducts to $\vec{\theta}$ be normal. The common bile duct was closed wi $T$ tube drainage and the liver and lymph node biopsied. Postoperatively the patient made goof progress for 2 days but then developed liver failure, hepatic coma and a septicaemia, dying 2 weeks after laparotomy.

Histology of the liver biopsy showed marked $\stackrel{\square}{\unrhd}$ parenchymal amyloid deposition with evidence of $\overrightarrow{\vec{B}}$ bile stasis. Amyloid deposition, accompanied by $\frac{0}{3}$ foreign body giant cells, was also found in the lymph $\bar{\partial}$ nodes. Post-mortem examination confirmed amyloidosis of the liver and upper abdominal lymph nodes, and also of the spleen. No other sites were 3 . involved. Furthermore, no other pathology or $\dot{\sigma}$ cause for the amyloid was found. In particular histological examination of the bone marrow was $\stackrel{8}{0}$ normal.

\section{Discussion}

Amyloidosis causing severe jaundice is rare. There have been 6 previously reported cases (Banwick, Berkman and Beaver, 1933; Orloff and o Felder, 1946; Atkinson, 1946; Barth, Willerson and N Waldman, 1969; Levy, Fryd and Eliakim, 1971; N Saunders and Child, 1960). All were males ranging from 44 to 62 years (mean 52 years).

Three of the patients presented with abdominal pain and one with indigestion. Only one patient $\stackrel{\mathscr{D}}{+}$ other than the present one was jaundiced at presentation and this was accompanied by pruritus and ascites. 
Not surprisingly, these patients caused diagnostic difficulties. Four underwent laparotomy, and in two even liver biopsies at the time of operation did not reveal amyloid. Liver function tests showed a similar pattern in all patients of increasing obstructive jaundice, a rising bilirubin accompanied by a markedly raised alkaline phosphatase where this estimation was available.

Three patients died of renal failure. Four of the patients had generalized amyloidosis at death. Where known, the livers were all enlarged. In only 2 cases was the diagnosis made an appreciable period before death and in three it was only made at post-mortem. All the patients had primary amyloidosis, as in the present case where no cause for the amyloid was found.

In the present case, the use of either ultrasonography (Malins and Sabel, 1972) or percutaneous trans-hepatic cholangiography (Elias et al., 1976) would have demonstrated the absence of a dilated biliary tree. The diagnosis could then have been made by percutaneous liver biopsy and the patient saved a laparotomy which only hastened his inevitable death.

\section{References}

AtKinson, A.J. (1946) Clinico-pathological conference. Gastroenterology, 7, 477.

Banwick, E.G., Berkman, J.M. \& Beaver, D.C. (1933) Diffuse amyloidosis: three unusual cases. A clinical and pathological study. Archives of Internal Medicine, 51, 978.

BARTH, W.F., Willerson, J.T. \& WALDMAN, J.A. (1969) Primary amyloidosis. American Journal of Medicine, 47, 259.

Brandt, K., Cathcart, E.S. \& Cohen, A.S. (1968) A clinical analysis of the course and prognosis of forty-two patients with amyloidosis. American Journal of Medicine, 44, 955.

Elias, E., Hamlyn, A.N., Jain, S., Long, R.G., SummerFIELD, J.A., Dick, R. \& SHERLOCK, S. (1976) A randomised trial of percutaneous transhepatic cholangiography with the Chiba needle versus endoscopic retrograde cholangiography for bile duct visualisation in jaundice. Gastroenterology, 71, 439.

LeVy, M., Fryd, C.H. \& Eliakim, M., (1971) Intra-hepatic obstructive jaundice due to amyloidosis of the liver. Gastroenterology, 61, 234.

Malins, S. \& SABEL, J., (1972) Ultrasonography in obstructive jaundice. Radiology, 123, 429.

Orloff, J. \& Felder, L. (1946) Primary systemic amyloidosis. Jaundice as a rare accompaniment. American Journal of Medical Science, 212, 275.

Saunders, R.J. \& ChILD, C.G. (1960) Primary amyloidosis with jaundice. Journal of the American Medical Association, 174, 1202. 